\title{
Analysis of the impact of simulation model simplifications on the quality of low-energy buildings simulation results
}

\author{
Marcin Klimczak ${ }^{1, *}$, Jacek Bojarski², Piotr Ziembicki ${ }^{3}$, and Piotr Kęskiewicz ${ }^{1}$ \\ ${ }^{1}$ Wroclaw University of Science and Technology, Faculty of Environmental Engineering, \\ ul. C.K. Norwida 4/6, 50-373 Wroclaw, Poland \\ ${ }^{2}$ University of Zielona Góra, Faculty of Mathematics, Computer Science and Econometrics, \\ ul. Prof. Z. Szafrana 15, 65-516 Zielona Góra, Poland \\ ${ }^{3}$ University of Zielona Góra, Faculty of Civil Engineering, Architecture and Environmental \\ Engineering, ul. Prof. Z. Szafrana 15, 65-516 Zielona Góra, Poland
}

\begin{abstract}
The requirements concerning energy performance of buildings and their internal installations, particularly HVAC systems, have been growing continuously in Poland and all over the world. The existing, traditional calculation methods following from the static heat exchange model are frequently not sufficient for a reasonable heating design of a building. Both in Poland and elsewhere in the world, methods and software are employed which allow a detailed simulation of the heating and moisture conditions in a building, and also an analysis of the performance of HVAC systems within a building. However, these systems are usually difficult in use and complex. In addition, the development of a simulation model that is sufficiently adequate to the real building requires considerable time involvement of a designer, is time-consuming and laborious. A simplification of the simulation model of a building renders it possible to reduce the costs of computer simulations. The paper analyses in detail the effect of introducing a number of different variants of the simulation model developed in DesignBuilder on the quality of final results obtained. The objective of this analysis is to find simplifications which allow obtaining simulation results which have an acceptable level of deviations from the detailed model, thus facilitating a quick energy performance analysis of a given building.
\end{abstract}

\section{Introduction}

A rise in energy consumption in a global scale is unavoidable [1-9]. It is a measure of success of the economy and community of a given country. The highest increase of energy consumption concerns the consumption of electric energy and fossil fuels (mainly in transportation). It is also very likely to reverse the current, decreasing trend concerning heat demand in urban agglomerations due to the more and more popular technologies of using heat for the production of other forms of energy, for example, cooling (most frequently in

* Corresponding author: marcin.klimczak@pwr.edu.pl 
the form of the so called "chilled water") for the needs of air-conditioning systems in buildings serving various purposes. This may result in increasing the production of district heat (generated and distributed in the district heating systems).

Rationalisation of heat use can and should be implemented in two different directions. The first is connected with enhancing the efficiency of heat sources and heating networks, whereas the other concerns a reduction of the demand for this type of energy by affecting and convincing designers of buildings and installations, as well as their users, to increase their activity and to take appropriate actions in order to optimize energy efficiency of buildings being designed and also to implement actions that would improve the technical parameters of already existing buildings. It should be underlined that optimisation of energy efficiency of buildings cannot be performed without employing advanced computer technologies, including building energy simulations and modern BIM technologies (Building Information Modelling). Currently, there are many types of programmes available on the market, which are used for energy optimisation of buildings, heating networks and district heating substations. These applications vary in their capabilities, the quality of results obtained and in the level of their complexity. In fact, the latter in many cases limits the utilization of these applications only to specially trained engineers. Moreover, professional software, especially BIM type systems, is very expensive to buy and to operate and this fact hinders or sometimes even makes it impossible for smaller design offices to use it. In this context, it is of crucial importance to develop a methodology for introducing simplifications to the building simulation model that would not affect adversely the quality of simulation results, and at the same time would make it possible to shorten the time and reduce the costs of building energy simulations.

\section{Building energy analysis}

In order to minimize energy consumption in a building, it is necessary to know its energy characteristics, consumption profile and understand how heat sources and the heating system work. In reality, it is difficult to obtain all the information while analysing the building or making its inventory, since quite frequently the documentation of the building is not up-to-date or incomplete and the performance data are not available. The problem can be solved by running an identification analysis of the system, i.e., the building, by means of developing computer simulation models and their calibration with the use of data obtained when the building is in use. A similar methodology should be used in order to analyse in detail the operation of the heat source, the heating system and domestic hot water supply.

In the literature, the notion of model is defined in many different ways. For the needs of this study, the definition given by Krupa [4] was adopted. According to the definition, a model is a set of variables and relations among them which are represented as an equation or a system of equations. The basic aims for which models of systems are developed include: description and explanation of the system's operation, prediction of its behaviour, impact on the environment and also optimization of its parameters.

According to Malinowski, the level of detail is one of the most important elements taken into consideration during the development and verification of the model [5]. It can be stated that the larger the model, the more realistic it is and simulation results resemble the reality. Practice shows, however, that a reasonable introduction of limitations in the level of data detail to the model is both economically and technically justifiable. Identification of a system considering numerous details requires much effort and is time consuming and this in turn results in higher costs which must be substantiated by the weight of the problem. In addition, once a detailed model is developed and implemented, the costs of the necessary software and the time of its operation are increasing. The costs of testing also rise, the number of data increases as well as the difficulties in manipulating the system's features. It 
happens frequently that satisfactory results are obtained after the first run of computer simulation and an introduction of further details to the model does not result in their better quality. If such instances are avoided, the time for the development of the model and time of simulations are reduced. According to Krupa, model equations can be solved analytically, numerically or by simulation [4]. In the latter case, the characteristic feature is that independent variables of the model are always the variables which correspond to the input values of the real system. Thanks to this the "experiment" run in the computer system, in structural terms, corresponds exactly to the experiment in the real system. A simulation may "condense" the time to such an extent that it is possible to simulate a couple of years of the system's operation within a very short time. It also allows an "expansion" of the system operation time and in consequence a detailed structure of the changes in the real system, which could not be observed in real time, can be examined. The essential advantages of computer simulations make it possible to experiment, check and compare new systems or to make proposals as to the introduction of changes to the existing systems. This method also enables an examination of hypothetical systems, whose testing in any other way would be dangerous or impossible.

It should be emphasized that a complete identity of model outputs and the real system should not be expected. It follows, among others, from the fact that the model expresses not all, but only the significant features of the system, and what is considered to be significant depends on the modelling objectives. Moreover, exact values of all real system inputs are generally not known. The fact, whether the differences observed between model outputs and system outputs permit the use of the model, is determined by the results of compatibility tests, whose content depends on the intended use of the model.

\subsection{Simulation software}

The issues of energy simulation of buildings, heat sources, heating systems and domestic hot water supply have been studied for more than 40 years. The studies have resulted in the development of a great number of computer programmes and applications of different functionality and level of complexity, from spreadsheets to specialist simulation tools (e.g. DesignBuilder, EnergyPlus, Polysun, TSOL), which combine various aspect of building design $[1,11]$.

All simulation calculations were made with the use of EnergyPlus simulation software, which is intended for carrying out building energy analysis. It has an added capability of making a detailed simulation of the heat load and annual energy consumption. By using EnergyPlus, the demand for heating, cooling and electric energy, which must be supplied to the building in order to maintain the required standards of comfort, can be simulated on the basis of a detailed description of the building, its installations and fittings. Moreover, an analysis of primary energy consumption renders it possible to determine the energy efficiency of the building and this, in consequence, may constitute the basis for drawing conclusions as to the introduction of constructional and functional changes in the building that would reduce energy consumption. It is worth emphasizing that at present it is the most modern and most advanced calculation tool designed for that purpose. It should be underlined that EnergyPlus is a software that does not have a graphical user interface. The application comprises only an engine which includes complete calculation (simulation) procedures and defined input and output as simple ASCII text files. This solution enables development of the graphical user interface (GUI) by external companies, thus it allows designers to focus on its intuitive character and functionality and relieves them from programming the computational algorithms (which are programmed by EnergyPlus programmers). Additionally, input and output data defined as simple text files facilitate the exchange of data between the engine and the GUI. This ensures stability of the whole 
package and improves the reliability of the programme as it allows an analysis of the correctness of the input and output data at each stage of the system operation.

Advanced calculation capabilities of EnergyPlus and its popularity have created interest in developing applications being a graphical user interface, which facilitate data entry and display of simulation results both in a text and graphical form (charts, visualizations of heat flow, etc.) Currently, many applications of this type are being developed, but DesignBuilder software is one of the most popular and offers most capabilities. The software is dedicated to developing 3D models of buildings with the use of a rich database of predefined building materials, construction of walls and installations. This, in combination with the inheritance of the features by successive elements defining the level of detail of the building description, allow a quick and precise modelling of buildings.

\section{Simulation models of the building under analysis}

Simulation analyses were performed for a multi-family low energy residential building localized in the $2^{\text {nd }}$ climate zone (the city of Legnica), in which the external design temperature is $-18^{\circ} \mathrm{C}$. The information on the building comprising its architecture, constructional parameters (internal and external walls, floors, flat roofs, glazing, etc.), type of use, localization, etc., were adopted on the basis of the design documentation. The fundamental parameters of the building are as follows:

- number of flats: 30

- dimensions of the building (width x length): $12.5 \times 36.5 \mathrm{~m}$

- total floor area: $2305.10 \mathrm{~m}^{2}$

- total building volume: $6856.57 \mathrm{~m}^{3}$

- $\quad$ heated area: $1987.28 \mathrm{~m}^{2}$

- $\quad$ heated building volume: $6035.76 \mathrm{~m}^{3}$

- maximum hourly power: $26.1 \mathrm{~kW}$

All variants of the building energy simulation were made on the basis of identical meteorological data (typical meteorological years and statistical weather data for Poland for building energy calculation published by the Ministry of Infrastructure and Development in 2008) for the region where the entity being modelled is situated. The models considered the actual location of the building in relation to the four cardinal points of the compass. The results of analyses presented in the paper comprise only energy demand for heating.

For the purpose of analysing the feasibility of introducing simplifications of the building description to the simulation model, four variants of simulation calculations were developed into which building description simplifications were introduced. A statistical analysis of simulation results was carried out for each variant of the simulation model (hourly data comprising, among others, temporary heating power and heat consumption). Figure 1 illustrates graphically the simulation model variants. The "Vsc" variant was the reference simulation model (base model). The model comprises a complete description of the building including all internal walls (divided into thermal zones), separation of stairways, flats and bathrooms in each of them. Additionally, shading elements on the facade were considered in the reference simulation model. Temperatures in individual, separated thermal zones, the amount of ventilation air and other essential parameters for the heat energy balance calculations were adopted in accordance with applicable regulations and standards. 


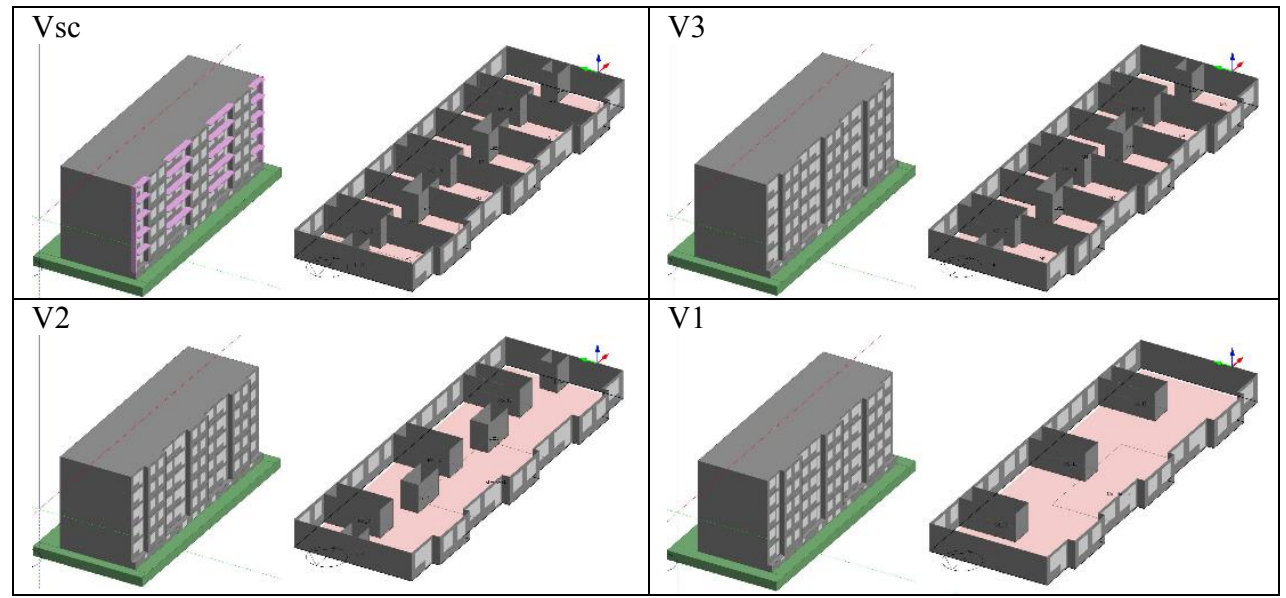

Fig. 1. Simulation model variants.

In the "V3" variant of the simulation model, shading elements (without changing the internal construction) were excluded, and this affected the heat gains caused by solar insolation. However, in the "V2" variant of the simulation model internal walls separating individual flats were additionally included, and thus the living area at each storey (except for the bathrooms) was treated as a whole. The simulation model in the "V1" variant differs from the "V2" variant in that it does not include "bathroom" thermal zones in each of the flats. This forced using an average temperature for the whole heated building volume (except for the stairways). In all the variants of the simulation model, averaged internal heat gains from occupancy, equipment, lighting of premises were adopted. Each zone was assigned the values of internal heat gains on the basis of the applicable regulations and standards.

In the preliminary simulation analyses, directly neighbouring buildings were taken as shading elements. An option of the programme was employed, which allows defining the geometry and precise location of such shading elements. The programme calculates in a ten-day step the annual shading caused by these buildings. However, in the final versions of the simulation model variants, the effect of shading exerted by the neighbouring buildings was excluded, since this parameter had a negligible effect on the final simulation results.

\section{Building simulation results}

Statistical analysis was performed using $\mathrm{R}$ Statistical Software [12] and ggplot package [13]. Table 1 summarizes building simulation results for all individual simulations. The maximum hourly heating power demand for the reference variant was $26.09 \mathrm{~kW}$, whereas specific energy consumption was $18.6 \mathrm{kWh} /\left(\mathrm{m}^{2} \mathrm{a}\right)$. The exclusion of shading (variant V3) caused an increased possibility of using solar heat gains. This in consequence resulted in a slight decrease of the maximum hourly heating power and a reduction in energy consumption. An additional exclusion of internal walls (variant V2) brought about a slightly smaller possibility of obtaining solar gains and reduced the possibility of heat accumulation in internal walls. In consequence, the required maximum hourly heating power (in comparison with Vsc) as well as energy consumption increased. The exclusion of the "bathroom" zone (variant V1) resulted in a slight decrease in the living zone temperature (an average temperature when bathrooms are included should be $20.2^{\circ} \mathrm{C}$, 
whereas the temperature of $20.0^{\circ} \mathrm{C}$ was adopted for calculations). This caused a reduction in energy consumption (compared to the Vsc variant by $8 \%$ ). However, it was not relevant for the maximum hourly power, which did not change in comparison with the previous variant.

Table 1. Summary of simulation results for individual variants.

\begin{tabular}{|c|c|c|}
\hline Variant & $\begin{array}{c}\text { Specific energy consumption, } \\
\mathbf{k W h} /\left(\mathbf{m}^{\mathbf{2}} \mathbf{a}\right)\end{array}$ & Maximum hourly power, $\mathbf{k W}$ \\
\hline Vsc & 18.6 & 26.09 \\
\hline V3 & 17.9 & 26.03 \\
\hline V2 & 18.2 & 26.28 \\
\hline V1 & 17.1 & 26.28 \\
\hline
\end{tabular}

Figure 2 illustrates temporary heating demand (in an hourly step) for the simulated Vsc and V1 variants. It should be pointed out that the direction of changes in the model operation cannot be determined explicitly from the graph (for instance, the reduction of heat consumption in comparison with the reference model). Thus, coefficients, which allow correction of the results obtained in the case the simulation models are simplified, cannot be clearly determined.

Figure 3 presents charts which describe the relations between the reference variant and other individual variants. The solid straight line represents the exact convergence of the data of individual models. It should be noted that for high power due to low external temperatures, in all the cases the data are convergent (and this causes such insignificant changes in the maximum hourly heating power). For lower values of power, the differences between individual variants are affected by solar gains and heat accumulation in walls of the building. It is most visible in the chart illustrating the relations between the Vsc and V3 variants. In this case, an increase in heat demand is seen in the Vsc variant compared to the V3 variant, in which the possibility of using solar gains by excluding external shields was increased. In the remaining cases, changes in power occur on both sides (variants), but they do not cause significant changes in the cumulative energy demand.

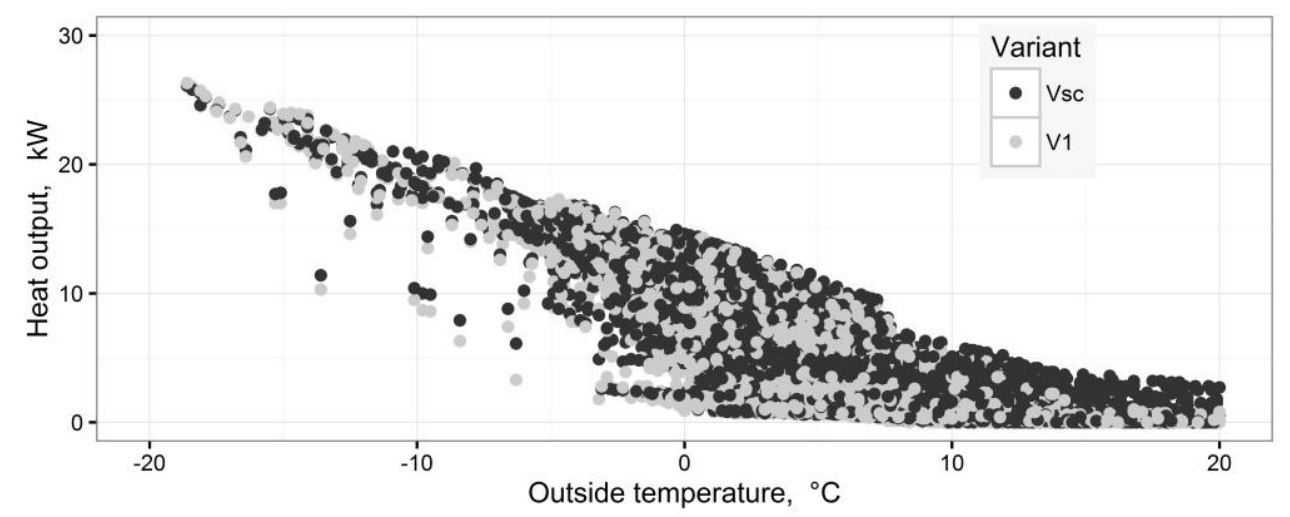

Fig. 2. Power distribution versus external temperature for the Vsc and V1 variants.

Figure 4 shows histograms illustrating the frequency of the results [of total 8760 (365days $* 24$ hours) results] with power deviation of a specific value (difference in 
power at the same hour in a year) in $\mathrm{kW}$ between the reference Vsc variant and other variants.

It should be noted that most of the results differ insignificantly (less than $0.25 \mathrm{~kW}$ ) from the value calculated in the reference model (at the maximum hourly power of $26 \mathrm{~kW}$ ).
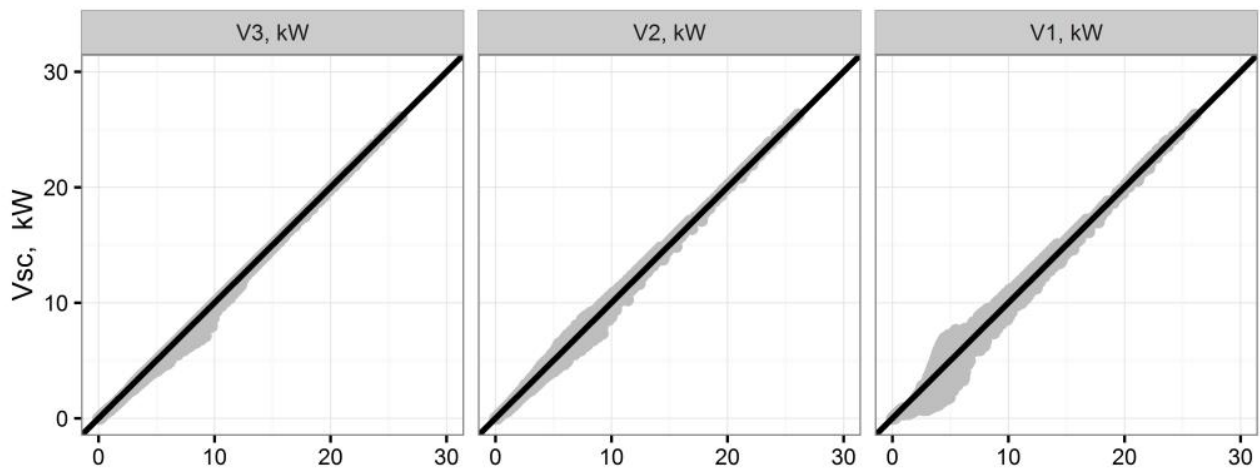

Fig. 3. The relation between the Vsc reference variant and other variants.

Also, in this case a distinct one-sided power reduction is noted when the existing elements which shade the building are excluded. As predicted, the biggest differences occur when extreme simulations are compared. The differences in hourly power demand range from 1.5 to $2.5 \mathrm{~kW}$ in less than $10 \%$ of observations.
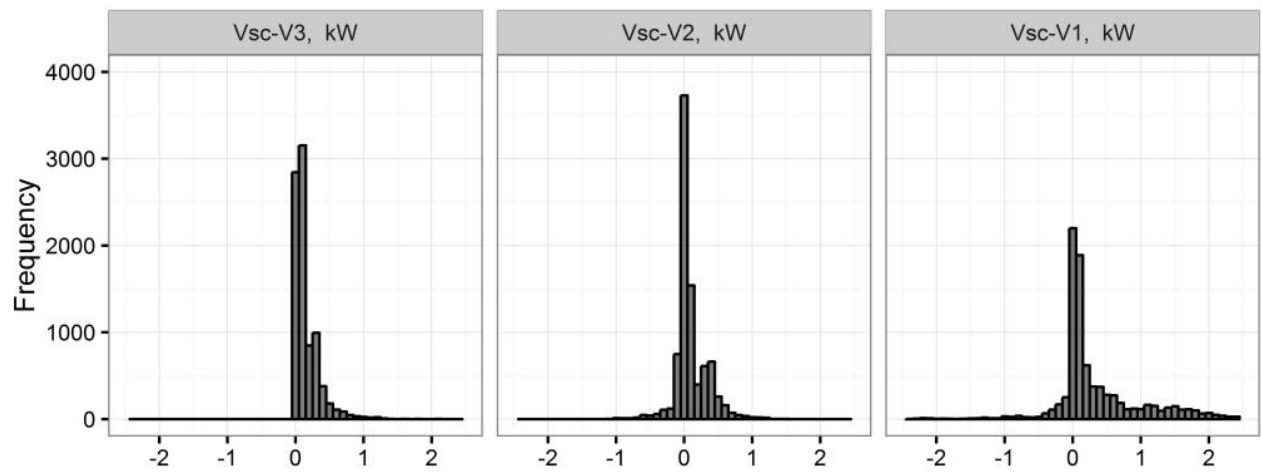

Fig. 4. Histogram illustrating the frequency of the results with power deviation between the Vsc reference variant and other simulation model.

\section{Conclusions}

While developing a building simulation model, it should always be taken into consideration how accurate and detailed should the model of the real building be and what discrepancies will follow from individual simplifications that are adopted. The adoption of a very detailed model involves a significant increase in the time required for the development and carrying out simulations, which translates into decidedly higher costs. The article presents a selected range of applicable simplifications of the model. Attention was focused exclusively on the construction of the building. The smallest differences in heat demand between the reference 
Vsc model and the simplified model were obtained when the effect of shading exerted by the building's own elements (e.g. balconies) was excluded. In the event such shading occurs on the north-facing side, its exclusion will not have a significant impact on heat demand. In the event of shading on the south-facing side, considerable glazing of the building and in the calculations of cooling demand, it must definitely be considered whether or not shading should be included in the model. Such an inclusion will unfortunately increase the time required for entering data into the simulation programme. In the event, not individual spaces of the building, but the building as a whole is analysed, it is worth considering a simplification of the construction by excluding the division into thermal zones. Such a solution reduces significantly the time needed for the development of the model and does not bring about significant changes in the heat demand calculation results. When an analysis of individual spaces (e.g. for the purpose of selecting individual heating and ventilation solutions) is made, such a simplification is inadmissible. However, a possibility of combining several zones of similar internal temperatures should always be considered as it will simplify the model considerably and reduce the time required for its development. An introduction of too many zones may hinder simulation of such a model or, in an extreme case, it may necessitate running the simulation with the division into two or three periods.

\section{References}

1. V. Harish, A. Kumar, Renewable and Sustainable Energy Reviews 56, 1272-1292 (2016)

2. IEA. World Energy Outlook 2012, International Energy Agency (2012)

3. Y. Keho, Energy Policy 91, 233-246 (2016)

4. K. Krupa, Modelowanie symulacja i prognozowanie (WNT, 2008)

5. P. Malinowski, Modelowanie hydrotermiczne i optymalizacja systemów zaopatrzenia w ciepło (Politechnika Wrocławska, 2009)

6. J. Malko, Energy Policy Journal 18, 1, 5-14 (2015)

7. L. Perez-Lombard, J. Ortiz, C. Pout, Energy and Buildings 40, 3, 394-398 (2008)

8. K. H. Solangi, M. R. Islam, R. Saidur, N. A. Rahim, H. Fayaz, Renewable and Sustainable Energy Reviews 15, 9, 2149-2163 (2011)

9. C. Wolfram, O. Shelef, P. J. Gertler, How will energy demand develop in the developing world? Working Paper 17747 (National Bureau of Economic Research, 2012)

10. P. Ziembicki, J. Bernasiński, M. Klimczak, i in. Rozproszone kogeneracyjne źródła energii dla budynków (Oficyna Wydawnicza Uniwersytetu Zielonogórskiego, Zielona Góra, 2013)

11. M. Trcka, J.L. Hensen, Automation in Construction 19, 93-99 (2010)

12. R Core Team. R: A Language and Environment for Statistical Computing. R Foundation for Statistical Computing, Vienna, Austria (2016)

13. H. Wickham. ggplot2: Elegant Graphics for Data Analysis. Springer-Verlag New York (2009) 